\title{
Early Predictors for Basic Numerical and Magnitude Competencies in Preschool Children-Are They the Same or Different regarding Specific Subgroups?
}

\author{
Silvia Pixner, Christina Kraut, Verena Dresen \\ UMIT, Institute for Psychology, Hall in Tyrol, Austria \\ Email: silvia.pixner@umit.at
}

How to cite this paper: Pixner, S., Kraut, C., \& Dresen, V. (2017). Early Predictors for Basic Numerical and Magnitude Competencies in Preschool Children-Are They the Same or Different regarding Specific Subgroups? Psychology, 8, 271-286.

http://dx.doi.org/10.4236/psych.2017.82016

Received: November 14, 2016

Accepted: January 20, 2017

Published: January 23, 2017

Copyright $\odot 2017$ by authors and Scientific Research Publishing Inc. This work is licensed under the Creative Commons Attribution International License (CC BY 4.0).

http://creativecommons.org/licenses/by/4.0/

\begin{abstract}
Basic numeric competencies in early childhood are found to be good predictors for later mathematical achievement. Therefore, it is of broad interest how specific predictors in early childhood, which are held responsible for a better arithmetic development later on, can be found. Our study aims to conduct more information to this topic and hence to extract factors that can already predict the basic numerical and magnitude competencies in preschool. Based on a sample of 188 preschoolers from 26 different kindergartens throughout Tyrol, we wanted to prove whether the factors of phonological awareness, counting abilities, fine motor skills, visual-spatial perception, motoric coordination as well as the children's age, their gender or handedness may be considered as possible predictors for later mathematic skills. Our data analysis revealed that only phonological awareness, counting abilities and children's visual-spatial perception pose significant predictors specifically for the basic numerical and magnitude competencies in preschoolers. In a second step, we tested whether these predictors are the same or different regarding two subgroups from our sample including children with different requirements. We found that children with different skills (concerning phonological awareness) might choose different strategies to acquire new competencies; therefore, different predictors are relevant for basic numerical and magnitude competencies. Regarding over all arithmetic competencies it is equal which predictor leads to basic numerical and magnitude competencies, children's performance did not differ.
\end{abstract}

\section{Keywords}

Early Predictors, Arithmetic Competencies, Mathematical Skills, Children, Early Arithmetic Development, Phonological Awareness, Counting Abilities, 
Visual-Spatial Perception

\section{Introduction: Early Development of Understanding Numbers and Quantities}

The ability to read and write numbers and to capture their meaning is an essential step in every child's development and a requirement for mastering later daily life. Skills that were acquired in the early stages of development are stable predictors for following progress and shown achievements. The development of understanding numbers and quantities starts in early childhood, long before children are introduced to formal education. Infants already have a fundamental understanding that lets them differentiate small quantities, such as 2 vs. 3 (Feigenson, Carey, \& Hauser, 2002). They are able to detect ordinal relations between two quantities and therefore are able to decide between a bigger and a smaller quantity (Brannon, 2002). Following research even brought to light that 6-month-old infants are able to distinguish larger quantities from each other (8 vs. 16) as long as these quantities show a relation of 1:2 (Brannon, Abbott, \& Lutz, 2004). Researchers assume that infants already develop an approximate number system that allows them to capture a quantity quite quickly. To what extent the differentiation between two quantities works out is dependent on the relation between them. In addition to the assumption of an approximate number system, another preverbal number system is postulated. Apart from the approximate number system, which is associated with non-symbolic representations and helps with differentiating between two quantities, there is an exact number system which implies a detailed understanding of (smaller) numbers (Wynn, 1992b). First and foremost, children learn a list of number words that they quickly link with certain actions and methods of counting. Around the age of two and a half, children start to count. At this point children are usually able to repeat number series like little poems without knowledge about the meaning of these numbers and the quantities behind them (Wynn, 1992b). Moreover, children at this stage of the counting development usually don't realize that every counted object is dedicated to one number word. With the acquirement of the cardinality principle children acquire the understanding that the last number word, when counting a quantity, is not only associated with the last counted object, but represents the complete quantity. Children who understand the cardinality principle for 1 and 2 are able to hand over exactly one or two objects after they are asked to do so. When the same children get asked for three or four objects they usually hand more than two objects that can be three or four objects by chance (Sarnecka \& Carey, 2008). This has to be considered even when children in this stage of development often can count beyond five and are proficient in understanding the stable order principle (maintaining the order of all number words while counting) and the one-to-one-correspondence principle (assigning each number word to a counted object). The meaning of the first three or four 
number words is learned one at a time and in chronological order (Sarnecka \& Lee, 2009). Between learning the cardinality for e.g. two and then three, weeks or month can go by. Once the children figure out the cardinal principle for the smaller numbers (up to three or four) they generalize this principle to the rest of their counting list (Negen \& Sarnecka, 2015).

\section{Importance of Early Arithmetic Skills and Later Mathematical Achievement}

The knowledge that arithmetic competencies evolve one after another and over a longer period of time is seen in the instance that children still show different abilities for handling numbers and quantities at the beginning of formal schooling (Libertus, Feigenson, \& Halberda, 2011). Therefore, the registration of early arithmetic skills and the development of number sense is a strong measure to predict later achievement in the arithmetic field. Children that already handle quantities quite well show better performances in mathematic tasks later on compared to other children of the same age (Starr, Libertus, \& Brannon, 2013). Hence, mathematic competencies in early childhood are a strong predictor for later mathematic performance (Locuniak \& Jordan, 2008). Aunola, Leskinen, Lerkkanen and Nurmi (2004) also found that children who show a higher level of arithmetic skills from the beginning have a much higher increase in their following arithmetic development. Children with much less positive preconditions show a less rapid development by comparison. The interindividual differences even increase up to school age. Children that already start with arithmetic problems in the early stage are in large part not able to catch up with children that start with good competencies (Jordan, Kaplan, Ramineni, \& Locuniak, 2009). Early arithmetic competencies consequently provide a basis for upcoming mathematic development. Because of that we naturally aspire to support numeracy and the understanding of quantities from early age on to maintain the development of innate arithmetic skills. With the help of programs for early support one aims to prevent that some children would fall behind the performance of their peers with the start of formal schooling (Gersten, Jordan, \& Flojo, 2005).

\section{Predictors for Later Understanding of Numbers and Quantities}

When children enter school age they usually show different competencies in handling numbers and quantities, which is due to several factors. Innate predispositions in handling quantities, domain-specific factors (tasks that include numbers or quantities) or general cognitive skills (domain-unspecific factors like language and phonological awareness, working memory, executive functions, visual-spatial competencies and the IQ) generate a basis for the differences in arithmetic development up until formal schooling (e.g. Kroesbergen, Van Luit, Van Lieshout, Van Loosbroeck, \& Van de Rijt, 2009). Aside from unspecific cognitive skills like nonverbal intelligence and the access speed to long-term memory that have an indirect effect on school performance we want to highlight 
and discuss specific predictors for later arithmetic competencies found in previous research such as visual perception, counting strategies, understanding of cardinality, language and phonological awareness. In this connection we are interested whether these specific predictors (especially regarding the phonological awareness) are the same or different for all children or not.

\subsection{Visual-Spatial Perception}

Hardly surprising, visual-spatial perception is a potential predictor for development of mathematic competencies when we consider the way of processing quantities at the beginning of infantile development. Particularly the spatial extension in a given room holds an important part. Long before infants are able to understand or discriminate numbers they differentiate between two quantities based on their spatial position. One object takes usually more space on a background than two objects and therefore can be identified as different (see e.g. Brannon, Abbott, \& Lutz, 2004). A good spatial orientation on this task could also be connected to spatial orientation in a number range. The skills necessary for a young child learning to count or to eventually perform simple arithmetic problems require visual-spatial abilities and even motoric coordination plus the ability to integrate perceptual and motor processes (Assel, Landry, Swank, Smith, \& Steelman, 2003). Krajewski and Schneider (2009) discovered that visual-spatial competencies directly influence developing mathematic skills. Visual-spatial skills were found to provide an early foundation for both executive processing and later mathematic abilities (Assel et al., 2003).

\subsection{Counting}

Connected to the idea of orientation in a number range we should mention counting strategies. The early skill to count and to use different strategies to do so is considered as an important predictor for mathematic performance (Duncan, Dowsett, Claessens, Magnuson, Huston, Klebanov et al., 2007). Children at the age of kindergarten that developed good counting skills are found to be better at calculations in school, whereas children with less distinct knowledge in counting before school enrolment show inferior performances in calculation operations (Fritz \& Ricken, 2008). Generally, children who already have a profound understanding of counting principles in preschool indicate better arithmetic achievements in first grade (Stock, Desoete, \& Roeyers, 2009).

\subsection{Use of Fingers in Counting}

First counting skills are almost always attended by the use of the fingers, hence, we will take a closer look on this phenomenon. Although the use of the fingers is seen as an implication to counting already for a while, we know today that the use of the fingers holds an important role in the development of arithmetic competencies (Eckstein, 2011). In consideration of finger-based representations during counting and calculating there are two different views that evolved during the last years. Moeller, Martignon, Wessolowski, Engel and Nuerk (2011) 
argue that finger-based strategies are exclusively used at the beginning of the development of counting. After a while (usually at the end of first grade) children unlearn the finger-based representations and replace them with more abstract numeric representations. Finger-based representations are in that matter just seen as a device for the transition to more complex mental representations. Contrary to the claims of Moeller and his colleagues, Eckstein (2011) believes that finger-based strategies are not exclusively used in children. Even adults may use the help of their fingers to support counting processes. This indicates that the influence of finger-based representations persists into adulthood. Apart from pure verbal counting the use of the fingers marks an important role in current research. Eckstein (2011) was able to conclude that the representation of numbers on the fingers is relevant for the acquisition of numerosity. Along with these assumptions Butterworth (1999) found that there might be a close connection between fingers, counting and number. The use of fingers does not only play an important role in the development of counting. Eckstein (2011) found, that good finger-based numeric representations can lead to better arithmetic performances later on in the school career.

Whenever one mentions the use of fingers in counting, the concept of handedness naturally comes to mind. It has been of common interest, how both hands are used during the process of counting (e.g. Lindemann, Alipour, \& Fischer, 2011). There is a cultural difference in the way children use their hands and fingers to count. People from western countries generally use their left hand to start counting and associate their left thumb with the number one. These findings are connected with the SNARC-Effect that includes a dominance of the mental number line proceeding from left to right. The SNARC-Effect describes that in a parity task small numbers are faster analyzed with the left hand and vice versa big numbers with the right hand (Dehaene, Bossini, \& Giraux, 1993). In the study by Lindemann, Alipour and Fischer (2011) participants from middle eastern countries mostly started counting with their right hand and used the little finger of their right hand to represent the number one. Additional research provided insight into the use of two hands or just one hand in counting. Whereas in western cultures we usually use two hands to count over five, Chinese culture for example provides a different coding of numbers which results in the prevalent use of just one hand in counting (Moeller et al., 2011). In the current study we want to include the previous research for the use of hands and fingers while counting and also the handedness of children in view of the connection to finger-based representations.

\subsection{Cardinality}

An important part of the counting strategies involves the cardinality principle. It develops later in time and marks a higher stage of development since it requires several earlier learning processes (Fritz \& Ricken, 2008). Before children are able to understand the principle of cardinality they have to inherit the stable order principle and the one-to-one correspondence principle (Gelman \& Gallistel, 
1978). An understanding of the cardinality principle is a key aspect in the development of infantile mathematical competency. Children that fully internalized the cardinality principle showed better performance on a task that measured the ability to estimate quantities (Moore, van Marle, \& Geary, 2016). Children that just showed an understanding of the cardinality for the numbers one and two, scored significantly lower on the same task. Those children, who still haven't developed an understanding of the cardinality principle at the end of kindergarten, run the risk for long-term difficulties in learning mathematics in school (Geary, Hoeard, Nugent, \& Bailey, 2012).

Connected to the acquirement of the cardinality principle is language. A strong correlation between the child's vocabulary and the knowledge of number words was found in a study by Negen and Sarnecka (2012).

\subsection{Language}

Young children are able to differentiate between quantities and therefore react to numbers from the first year of their life, even before they start to speak (Wynn, 1992a). Nevertheless, language plays an important role in the acquirement of numbers, their differentiation and their meaning (as mentioned before in the section about cardinality). Among the first vocabulary of a child there are always first number words too (Szagun, 2013). Children learn rather quickly that the number words are special and are treated differently than other words. Around two years, children learn to differentiate between "one" and "more" with the help of the language, i.e. the plural marking of nouns (Wynn, 1992b). This point is depended on the language itself. In a study by Sarnecka, Kamenskaya, Yamana, Ogura and Yudovina (2007) Japanese children showed later learning successes regarding this discrimination between one and more than English-speaking children, although, Japanese parents used number words just as often as American Parents. This is due to the different markings of the plural of nouns in number words, there is no such indication of the plural in the Japanese language compared to English.

\subsection{Vocabulary and Phonological Awareness}

As mathematical competencies language can be divided into different skills such as grammar and vocabulary. Various studies (e.g. Negen \& Sarnecka, 2012) indicate the expressive vocabulary as an important predictor for numerical competence. Negen and Sarnecka (2012) also found an important correlation between the child's vocabulary and the knowledge of number words. The expressive vocabulary is the best linguistic predictor for mathematic competencies. Neither speech comprehension nor grammar or conceptual aspects of language could show similar predictive power (Praet, Titeca, Ceulemans, \& Desoete, 2013). LeFevre, Fast, Smith-Chant, Skwarchuk, Bisanz, Kamawar et al (2010) were able to link linguistic competences as a predictor to later number knowledge and the understanding of numeral structure. Even though strong interactions between verbal und numerical competencies have been previously found, 
the influence of phonological awareness is still fairly overlooked. Referring to this, Lopes-Silva, Moura, Julio-Costa, Haase and Wood (2014) investigated whether phonological awareness has an effect on mathematic competencies. Their results show that phonological awareness has a significant impact on number transcoding by mediating the influence of the verbal working memory on the transcoding skills. De Smedt, Taylor, Archibald and Ansari (2010) additionally proposed that phonological awareness is clearly connected with the solution of mathematical problems that involve long-term memory. Moreover, phonological awareness is proven to influence later mathematical performance. Children with problems in phonological awareness run the risk to develop arithmetic and reading difficulties (Krajewski \& Schneider, 2009).

\section{Goals and Predictions of the Current Study}

Our study aims to identify possible predictors in preschool children that can specifically predict the ability for basic numerical and magnitude competencies as an element of arithmetic skills. Based on previous research we decided to include the factors phonological awareness, counting abilities, visual-spatial perception, motoric coordination, fine motor skills as well as the children's age, their gender and handedness. We hope that our study can primarily shed light on rather overlooked factors like the influence of phonological awareness on mathematical competencies and secondly replicate and possibly amplify existing assumptions on predictors. As an addition to existing research we wanted to pursue the question whether predictors are valid for all children or might change with different basic numerical competencies. Therefore we extracted subgroups from our sample. We wanted to test generally found predictors and define new predictors if needed in children with above-average phonological awareness plus poor or moderate competencies concerning visual-spatial abilities (subgroup 1) and in children with below-average phonological awareness plus very good or good visual-spatial abilities (subgroup 2).

\section{Method}

\subsection{Participants}

The sample for the current study portrays a representative probability sample that consists of participants taken part in a prevalence study in all regions throughout Tyrol. Overall 26 different kindergartens were involved in the study. The sample consists of 188 preschoolers, 96 male children and 92 females. The average age was four to 6 years of age with a mean value of (M) 68.02 months. 178 of the children were German native speakers, the remaining 10 preschoolers spoke a different, not further specified native language. The children's handedness was rather dissimilar, 160 children were right-handed, 24 left-handed, 4 children were left with no information about their handedness.

\subsection{Process of Data Collection}

The current study was approved by the Research Committee for Scientific and 
Ethical Questions of the UMIT, Hall, Tyrol, and the state education authority of Tyrol. Written informed consent was obtained from parents prior to the study and children were asked for their assent prior to assessment. Tests were directly organized by one out of a group of instructed/trained university students. All preschoolers were first tested in small groups of 3 to 5 children, after this the tests continued in individual settings. The test at a whole took around 40 to 50 minutes to finish. All settings started by a registration of demographic features (date of birth and gender) for each child. The information about the children's native language was added with the help of the parents' descriptions.

\subsection{Instruments and Procedure}

As a first step children's counting skills were measured. All children were advised to count as far as they can (at a maximum of 30 every child was stopped). The second question determined whether the children were able to count with a given lower and upper limit (i.e., to count from 5 to 9). Afterwards they were asked to count objects that were painted on a piece of paper. This task was used to evaluate the understanding of the stable order principle, the one-to-onecorrespondence principle and the cardinality principle. All tasks including counting were taken from the TEDI-MATH (Test zur Erfassung numerischrechnerischer Fertigkeiten vom Kindergarten bis zur 3. Klasse by Kaufmann, Nuerk, Graf, Krinzinger, Delazer, \& Willmes, 2009). Apart from counting skills children's handedness was focused on. To test the handedness the investigator handed different objects to the children and noted down which hand was preferably used to grab those objects. In a third category the children's counting skills by using their fingers were assessed. The investigator asked the preschooler to count till ten using the fingers. To precisely mark the used strategy every investigator drew the result on a prepared sheet. Every sheet contained drawings of both hands with firstly the palm and secondly the back of the hands. The investigator wrote down all counted numbers to the fingers on the sheet. For children who correctly assigned every number to one finger the investigator drew on the fingers on the sheet. For children who didn't assign every number to one finger the investigator of the test drew their result right next to the finger. At the end, the filled sheets gave detailed information about the number of fingers used, the stable order principle, the one-to-one-correspondence for each hand and the use of handedness referring to the use of the palm or the back of the hand while counting. Moreover, we obtained information which hand-respectively which finger was used first to start counting for every participant. Apart from the collection of information about counting strategies, more standardized tests assessing additional competencies were included in the study. The ability to determine quantities was assessed with 3 subscales ("Mengen vergleichen"-Comparing quantities, "Seriation von Mengen"-Seriation of quantities, "Zahl-MengenZuordnung"-Assignment of numbers and quantities) from the Eggenberger Rechentest 0+ (ERT 0+; Lenart, Schaupp, \& Holzer, 2014). Visual-spatial competencies were tested using the Beery-Buktenica Developmental Test for Visu- 
al-Motor Integrations (Beery VMI; Beery, Buktenica, \& Beery, 2010). All subscales of visual-motor integration, visual perception and motor coordination were used. To gather information about the children's phonological awareness we used the Gruppentest zur Früherkennung von Lese-und Rechtschreibschwierigkeiten (Barth \& Gomm, 2004).

\section{Results}

As a first step we had a detailed look at the results from the counting tasks. Out of the 181 valid data sets for the task of 'Counting up to the highest number', 72 preschoolers (39.8\%) were able to count correctly up to 30 . In total, $66.9 \%$ of our participants were able to count up to 20 and higher. $95.5 \%$ of the sample counted up to 10 or higher. For the next task, where the participants had to count the images of six lions, $95.1 \%$ of the children showed that they were able to count given objects correctly. $96.2 \%$ operated with the stable-order-principle (maintaining the order of all number words while counting) while counting. The one-to-one-correspondence principle (assigning each number word to a counted object) was applied by $97.3 \%$ of the participants. We assessed the cardinality principle by asking the children once more how much objects they counted in total without counting again. $89.6 \%$ of the preschoolers gave the right answer to that question. The descriptive data analysis also showed that $67 \%$ of the children use the palm of their right hand to start counting, $29.9 \%$ start with the palm of their left hand. Only $1.6 \%$ of the participants begin counting with the back of their right hand and $1.1 \%$ use the back of their left hand as a first guideline for counting. Out of the whole sample three children only used one hand to count, while all others used both hands when counting quantities over five. When the participants counted quantities over five, $67.6 \%$ of them used the palm of their left hand to count on. Respectively $31.3 \%$ of the children continued to count on the palm of their right hand. $0.5 \%$ of all preschoolers used either the back of their left or right hand to continue counting up to ten. Overall, 95.1\% started counting with their thumb when counting to ten. Only $3.3 \%$ of all participants used their little finger and $1.6 \%$ their index finger to start counting, other fingers were not used to start counting. The one-to-one-correspondence for the fingers was correctly displayed in $93.4 \%$ of the children for their first counting hand and in $86.2 \%$ for their second counting hand (Table 1).

Apart from the descriptive data for counting abilities, our primary aim was to determine predictors that could show the competencies in numerical and magnitude processing at the stage of preschool. For this research question a

Table 1. Overview of children's handedness and the preferred hand used when beginning to count.

\begin{tabular}{ccc}
\hline & Right hand & Left hand \\
\hline Right hander & $75.80 \%$ & $24.20 \%$ \\
Left hander & $14.30 \%$ & $85.75 \%$ \\
\hline
\end{tabular}


regression was run. The basic numerical and magnitude competencies were defined as the total score from all subscales taken from the ERT 0+ (Lenart, Schaupp, \& Holzer, 2014). We chose to include the factors phonological awareness, counting abilities, fine motor skills, visual-spatial perception, motoric coordination as well as the children's age, their gender and handedness as predictors into our analysis. Only three of these were proven to be significantly relevant factors. The stepwise linear regression showed that phonological awareness is the strongest predictor and explains $21 \%$ of the variance $\left(R^{2}=0.216\right.$, adjusted $\left.R^{2}=0.210, \beta=0.465, p<0.001\right)$. We extended our second model with the factor counting. The combination of the factors phonological awareness and counting explains $33.4 \%$ of variance $\left(R^{2}=0.344\right.$, adjusted $R^{2}=0.334, \beta$ phonological awareness $=0.379, p<0.001 ; \beta$ counting $=0.368, p<0.001)$. The extension of the factor visual-spatial perception led to the matter that all three factors explain $35.6 \%$ of variance $\left(R^{2}=0.371\right.$, adjusted $R^{2}=0.356, \beta$ phonological awareness $=0.346, p<0.001 ; \beta$ counting $=0.313, p<0.001 ; \beta$ visual-spatial perception $=0.178, p=0.020$ ) for the third model. All remaining predictors were not able to explain more significant variance and therefore were excluded from the model.

To verify whether all predictors are valid for all participants we ran two additional regression analyses. We formed two subgroups with participants who had above-average phonological awareness and co-occur poor or average visual-spatial abilities (subgroup 1) and another group with participants who showed below-average phonological awareness and co-occur above-average or average visual-spatial abilities (subgroup 2) (Table 2).

The group of participants with above-average phonological awareness was found to have only phonological awareness as a significant predictor for their basic numerical and magnitude competencies $\left(R^{2}=0.251\right.$, adjusted $R^{2}=0.194, \beta$ $=0.501, p=0.057)$. For the group with below-average phonological awareness only counting abilities revealed as a significant predictor for basic numerical and magnitude competencies $\left(\mathrm{R}^{2}=0.270\right.$, adjusted $\left.R^{2}=0.227, \beta=0.520, p=0.023\right)$. In a last step we analyzed the differences between the basic numerical and

Table 2. Classification of the sample for selecting two subgroups.

\begin{tabular}{|c|c|c|c|}
\hline & $\begin{array}{c}\text { Below-average } \\
\text { phonological } \\
\text { awareness }\end{array}$ & $\begin{array}{c}\text { Average } \\
\text { phonological } \\
\text { awareness }\end{array}$ & $\begin{array}{c}\text { Above-average } \\
\text { phonological } \\
\text { awareness }\end{array}$ \\
\hline $\begin{array}{c}\text { Below-average } \\
\text { visual-spatial } \\
\text { perception }\end{array}$ & 9 & 16 & $0^{*}$ \\
\hline $\begin{array}{c}\text { Average } \\
\text { visual-spatial } \\
\text { perception }\end{array}$ & $24^{*}$ & 83 & $19^{*}$ \\
\hline $\begin{array}{c}\text { Above-average } \\
\text { visual-spatial } \\
\text { perception }\end{array}$ & $4^{*}$ & 24 & 9 \\
\hline
\end{tabular}

* data we used for classification of the two groups. 
magnitude competencies of the two subgroups. The t-test showed no differences regarding the means (subgroup 1: $M=9.5$; Subgroup 2: $M=9.7 ; t(44)=0.374$; $p>0.05)$. To exclude, that both of our two separated subgroups are weak performers, we compared them with the rest of our sample (rest group; $M=9.80$ ), using t-tests (subgroup 1 with rest: $t(154)=0.539 ; p>0.05$; and subgroup 2 with rest: $t(164)=0.183 ; p>0.05)$, but no differences were found. This means that all children can reach the same level of basic numerical and magnitude competencies regardless of their impairment in the phonological awareness.

\section{Discussion}

The aim of the current study was to find factors actually influencing preschool children's abilities to assess quantities. Building upon and adapting from previous research concerning predictors for mathematical achievement, we decided to include the factors of phonological awareness, counting abilities, fine motor skills, visual-spatial perception, motoric coordination as well as the children's age, their gender and handedness into our research. Results of our analysis show that only three of the assumed factors actually act as significant predictors. In this instance phonological awareness was found to be the strongest predictor followed by the factors of counting and visual-spatial perception. Below, we will further evaluate our findings and discuss them considering previous research for predictors of basic numerical and magnitude competencies.

Firstly, we want to address the influence of phonological awareness as it was proven to be the strongest predictor for performance in basic numerical and magnitude competencies in preschool children. It is fairly unsurprising that phonological awareness plays an important role because generally strong interactions between verbal und numerical competencies have been found. LopesSilva, Moura, Julio-Costa, Haase and Wood (2014) previously determined the influence of phonological awareness on number transcoding in Brazilian children. We assume that phonological awareness might have an above-average influence on basic numerical and magnitude competencies in German too, because it requires actual knowledge about certain number words. The German words for one, two, three ("eins", "zwei", "drei") have very similar sounds and therefore must be fully understood to discriminate between them. Consequently, a fair level of skill and knowledge is required in order to master the task. Nevertheless, the influence of this specific aspect is still fairly overlooked in existing research and should be further elaborated because, as evidenced in our results, it has such a strong impact.

Secondly, we found counting abilities to be the second strongest influence on arithmetic skills. This finding is congruent with previous research in which the early skill to count and to use different strategies to do so is considered as an important predictor for mathematic performance (Duncan, Dowsett, Claessens, Magnuson, Huston, Klebanov et al., 2007). However, while it has been hypothesized that the children's handedness and the coherent use of their fingers could explain an important influence on their counting strategies and consequently on 
their arithmetic performance, there were no effects concerning the participants' handedness regarding basic numerical and magnitude competencies in our study. These findings support that handedness does not explain these competencies, that means, that children develop basic numerical and magnitude competencies independent of their handedness. It is possible that the influence of children's handedness and the use of their fingers might vary with their level of education and the resulting competencies (c.f. LeFevre, Smith-Chant, Fast, Skwarchuck, Sargla, Arnup et al., 2006) and therefore don't operate as significant predictors for our analysis. Lastly, we registered the factor visual-spatial perception as an important predictor for arithmetic achievement. We assumed an impact of visual-spatial components based on previous research by Assel et al. (2003) who proposed that besides motoric processes, visual-spatial skills highly impact children's ways of learning to count and to eventually perform arithmetic problems. Our results are also in line with findings by Krajewski and Schneider (2009), who propose that visual-spatial competencies have a direct stake in later arithmetic development.

Most importantly we could confirm that the predictors, as expected and in literature described, explain significantly the basic numerical and magnitude competencies in our participants and indicate their performances. Regarding the two subgroups, the predictors split up: In children with above-average phonological awareness, only phonological awareness remained a substantial predictor. We assume that these children use this strength strongly for developing new competencies, in our study to develop the basic numerical and magnitude competencies via the phonological awareness. Conversely, in the sample with below-average phonological awareness only early counting abilities acted as a predictor for basic numerical and magnitude competencies. This means that children with below-average phonological awareness can compensate this weakness and use another way to develop basic numerical and magnitude competencies. Regardless these differences in relevant predictors, our findings show no difference in developing basic numerical and magnitude competencies regarding these two subgroups. Concluding from that we can see that there are general predictors for basic numerical and magnitude competencies. However, these predictors are not valid for all children. For example, those who have above-average phonological awareness only need that one competency to perform well on mathematic tasks, whereas those who show below-average phonological awareness use other strategies (in this case counting strategies) to learn different competencies in basic numerical and magnitude understanding. These findings demonstrate that a specific weakness in one of these relevant predictors does not lead automatically to an impairment regarding the criterion, as long as other competencies for compensation are available. This should be considered more strongly and evaluated in following research.

Our results highlight the importance of phonological awareness, early counting abilities and visual-spatial skills as generally three significantly influencing factors on arithmetic abilities, which, therefore, should be in the focus of further 
research. As early numeracy and understanding numbers in preschool are two of the most important predictors for later arithmetic competencies and the development of mathematic skills at the beginning of formal schooling (e.g. Locuniak \& Jordan, 2008; Jordan et al., 2009), research should be directed towards that specific field of interest. Especially new support programs could be specifically targeted at children who already show arithmetic problems in the early stages of development in order to prevent these children from falling further behind in these abilities compared to their peers.

\subsection{Limitations of the Current Study}

One of the main limitations of this study is certainly the sample size of the two selected subgroups. Regarding only a subgroup with children with the combination of above-average competencies in phonological awareness and below-average visual-spatial competencies, would result in a subgroup size (as can be seen from Table 2) with 0 children. A similar pattern could be found on the other side of these extremes-the combination of children with below-average competencies in phonological awareness and above-average visual-spatial competencies. Therefore, it was necessary to include children with average visual-spatial competencies as well. Nevertheless, our data show a clear line, the assumed hypothesis could be clearly confirmed.

\subsection{Directions for Further Research}

Missing or deficient competencies in mathematical skills do have an essential impact on our whole lives. For this reason, research focuses on identifying risk factors and supporting skills already at an early stage. It should be mentioned that a person is not a summation of competencies, as well as not every risk factor must immediately lead to an impairment, but that influence of all supporting skills and risk factors is much more dynamic. For example, the results of the present study show that the phonological awareness is an important predictor of the basic numerical and magnitude competencies in children. Nevertheless, children with a below-average performance in phonological awareness and, at the same time, above-average visual-spatial competencies can achieve a similar level in basic numerical and magnitude competencies, as children from the other end of the extreme. This means that in development there is no "one and only way", but a way, mostly differing for each person, adapted to the strengths and weaknesses of the individual, and in the end still leading to the same or similar goal. This should be taken into account in following research in this specific field of interest.

\section{Acknowledgements}

This research was supported by Bildungsabteilung des Landes Tirol, Austria. We would also like to thank the school district councils of Tyrol, Austria and the respective school principals who gave permission to conduct this study. Furthermore, we wish to express our thanks to all participating children who dedicated 
their time and efforts to our project.

\section{References}

Assel, M. A., Landry, S. H., Swank, P., Smith, K., \& Steelman, L. M. (2003). Precursors to Mathematical Skills: Examining the Roles of Visual-Spatial Skills, Executive Processes, and Parenting Factors. Applied Developmental Science, 7, 27-38. https://doi.org/10.1207/S1532480XADS0701_3

Aunola, K., Leskinen, E., Lerkkanen, M.-K., \& Nurmi, J. E. (2004). Developmental Dynamics of Math Performance from Preschool to Grade 2. Journal of Educational Psychology, 4, 699-713. https://doi.org/10.1037/0022-0663.96.4.699

Barth, K., \& Gomm, B. (2004). Gruppentest zur Früherkennung von Lese- und Rechtschreibschwierigkeiten. Phonologische Bewusstheit bei Kindergartenkindern und Schulanfängern (PB-LRS). München: Reinhardt.

Beery, K. E., Buktenica, N. A., \& Beery, N. A. (2010). Beery VMI: The Beery-Buktenica Developmental Test of Visual-Motor Integration. Bloomington, MN: Pearson.

Butterworth, B. (1999). The Mathematical Brain. London, UK: Macmillan.

Brannon, E. M. (2002). The Development of Ordinal Numerical Knowledge in Infancy. Cognition, 83, 223-240. https://doi.org/10.1016/S0010-0277(02)00005-7

Brannon, E. M., Abbott, S., \& Lutz, D. J. (2004). Number Bias for the Discrimination of Large Visual Sets in Infancy. Cognition, 93, 59-68.

https://doi.org/10.1016/j.cognition.2004.01.004

Dehaene, S., Bossini, S., \& Giraux, P. (1993). The Mental Representation of Parity and Number Magnitude. Journal of Experimental Psychology: General, 122, 371-396. https://doi.org/10.1037/0096-3445.122.3.371

De Smedt, B., Taylor, J., Archibald, L., \& Ansari, D. (2010). How Is Phonological Processing Related to Individual Differences in Children's Arithmetic Skills? Developmental Science, 13, 508-520. https://doi.org/10.1111/j.1467-7687.2009.00897.x

Duncan, G. J., Dowsett, C. J., Claessens, A., Magnuson, K., Huston, A. C., Klebanov, P. et al. (2007). School Readiness and Later Achievement. Developmental Psychology, 43, 1428-1446. https://doi.org/10.1037/0012-1649.43.6.1428

Eckstein, B. (2011). Mit 10 Fingern zum Zahlenverständnis. Göttingen: Vandenhoek \& Ruprecht.

Feigenson, L., Carey, S., \& Hauser, M. (2002). The Representations Underlying Infant's Choice of More: Object Files versus Analog Magnitudes. Psychological Science, 13, 2. https://doi.org/10.1111/1467-9280.00427

Fritz, A., \& Ricken, G. (2008). Rechenschwäche. München: Ernst Reinhardt.

Geary, D. C., Hoard, M. K., Nugent, L., \& Bailey, D. H. (2012). Mathematical Cognition Deficits in Children with Learning Disabilities and Persistent Low Achievement: A Five Year Prospective Study. Journal of Educational Psychology, 104, 206-223. https://doi.org/10.1037/a0025398

Gelman, R., \& Gallistel, C. R. (1978). The Child's Understanding of Number. Cambridge, MA: Harvard University Press.

Gersten, R., Jordan, N. C., \& Flojo, J. R. (2005). Early Identification and Interventions for Students with Mathematics Difficulties. Journal of Learning Disabilities, 38, 293-304. https://doi.org/10.1177/00222194050380040301

Jordan, N. C., Kaplan, D., Ramineni, C., \& Locuniak, M. N. (2009). Early Math Matters: Kindergarten Number Competence and Later Mathematics Outcomes. Developmental Psychology, 45, 850-867. https://doi.org/10.1037/a0014939 
Kaufmann, L., Nuerk, H.-C., Graf, M., Krinzinger, H., Delazer, M., \& Willmes, K. (2009). TEDI-MATH. Test zur Erfassung numerisch-rechnerischer Fertigkeiten vom Kindergarten bis zur 3. Klasse. Bern: Verlag Hans Huber.

Krajewski, K., \& Schneider, W. (2009). Exploring the Impact of Phonological Awareness, Visual-Spatial Working Memory, and Preschool Quantity-Number Competencies on Mathematics Achievement in Elementary School: Findings from a 3-Year Longitudinal Study. Journal of Experimental Child Psychology, 103, 516-531.

https://doi.org/10.1016/j.jecp.2009.03.009

Kroesbergen, E. H., Van Luit, J. E. H., Van Lieshout, E. C. D. M., Van Loosbroeck, E., \& Van de Rijt, B. A. M. (2009). Individual Differences in Eary Numeryca. The Role of Executive Functions and Subitizing. Journal of Psychoeducational Assessment, 27, 226236. https://doi.org/10.1177/0734282908330586

Libertus, M. E., Feigenson, L., \& Halberda, J. (2011). Preschool Acuity of the Approximate Number System Correlates with School Math Ability. Developmental Science, 14, 1292-1300. https://doi.org/10.1111/j.1467-7687.2011.01080.x

Lindemann, O., Alipour, A., \& Fischer, M. H. (2011). Finger Counting Habits in Middle Eastern and Western Individuals: An Online Survey. Journal of Cross-Cultural Psychology, 42, 566-578. https://doi.org/10.1177/0022022111406254

LeFevre, J.-A., Fast, L., Skwarchuk, S.-L., Smith-Chant, B. L., Bisanz, J., Kamawar, D., \& Penner-Wilger, M. (2010). Pathways to Mathematics: Longitudinal Predictors of Performance. Child Development, 81, 1753-1767. https://doi.org/10.1111/j.1467-8624.2010.01508.x

LeFevre, J.-A., Amith-Chant, B. L., Fast, L., Skwarchuck, S.-L., Sargla, E., Arnup, J. S. et al. (2006). What Counts as Knowing? The Development of Conceptual and Procedural Knowledge of Counting from Kindergarten through Grade 2. Journal of Experimental Child Psychology, 93, 285-303. https://doi.org/10.1016/j.jecp.2005.11.002

Lenart, F., Schaupp, H., \& Holzer, N. (2014). ERT 0+: Eggenberger Rechentest 0+. Diagnostikum für Dyskalkulie-Disposition für das Ende des Kindergartenalters bis Mitte der 1. Schulstufe. Bern: Verlag Hans Huber.

Locuniak, M. N., \& Jordan, N. C. (2008). Using Kindergarten Number Sense to predict Calculation Fluency in Second Grade. Journal of Learning Disabilities, 41, 451-456. https://doi.org/10.1177/0022219408321126

Lopes-Silva, J. B., Moura, R., Júlio-Costa, A., Haase, V. G., \& Wood, G. (2014). Phonemic Awareness as a Pathway to Number Transcoding. Frontiers in Psychology, 5, 13. https://doi.org/10.3389/fpsyg.2014.00013

Moeller, K., Martignon, L., Wessolowski, S., Engel. J., \& Nuerk, H.-C. (2011). Effects of Finger Counting on Numerical Development? A Review of Neurocognitive Arguments and Those from Mathematics Education. Frontiers in Psychology, 2, 328. https://doi.org/10.3389/fpsyg.2011.00328

Moore, A. M., van Marle, K., \& Geary, D. C. (2016). Kindergartners' Fluent Processing of Symbolic Numerical Magnitude Is Predicted by Their Cardinal Knowledge and Implicit Understanding of Arithmetic 2 Years Earlier. Journal of Experimental Child Psychology, 150, 31-47. https://doi.org/10.1016/j.jecp.2016.05.003

Negen, J., \& Sarnecka, B. W. (2012). Number-Concept Acquisition and General Vocabulary Development. Child Development, 83, 2019-2027. https://doi.org/10.1111/j.1467-8624.2012.01815.x

Negen, J., \& Sarnecka, B. W. (2015). Is There Really a Link between Exact-Number Knowledge and Approximate Number System Acuity in Young Children? British Journal of Developmental Psychology, 33, 92-105. https://doi.org/10.1111/bjdp.12071

Praet, M., Titeca, D., Ceulemans, A., \& Desote, A. (2013). Language in the Prediction of 
Arithmetics in Kindergarten and Grade 1. Learning and Individual Differences, 27, 9096. https://doi.org/10.1016/j.lindif.2013.07.003

Sarnecka, B. W., \& Carey, S. (2008). How Counting Represents Number What Children Must Learn and When They Learn It. Cognition, 108, 662-674. https://doi.org/10.1016/j.cognition.2008.05.007

Sarnecka, B. W., Kamenskaya, V. G., Yamana, Y., Ogura, T., \& Yudovina, J. B. (2007). From Grammatical Number to Exact Numbers: Early Meanings of "One”, “Two", and "Three" in English, Russian, and Japanese. Cognitive Psychology, 55, 136-168. https://doi.org/10.1016/j.cogpsych.2006.09.001

Sarnecka, B. W., \& Lee, M. D. (2009). Levels of Number Knowledge during Early Childhood. Journal of Experimental Child Psychology, 103, 325-337. https://doi.org/10.1016/j.jecp.2009.02.007

Stock, P., Desoete, A., \& Roeyers, H. (2009). Mastery of the Counting Principles in Toddlers: A Crucial Step in the Development of Budding Arithmetic Abilities? Learning and Individual Differences, 19, 419-422. https://doi.org/10.1016/j.lindif.2009.03.002

Starr, A., Libertus, M. E., \& Brannon, E. M. (2013). Number Sense in Infancy Predicts Mathematical Abilities in Childhood. Proceedings of the National Academy of Sciences, 110, 18116-18120. https://doi.org/10.1073/pnas.1302751110

Szagun, G. (2013). Sprachentwicklung beim Kind. Weinheim: Beltz Verlag.

Wynn, K. (1992a). Addition and Subtraction by Human Infants. Nature, 358, 749-750. https://doi.org/10.1038/358749a0

Wynn, K. (1992b). Children's Acquisition of the Number Words and the Counting System. Cognitive Psychology, 24, 220-251. https://doi.org/10.1016/0010-0285(92)90008-P

Submit or recommend next manuscript to SCIRP and we will provide best service for you:

Accepting pre-submission inquiries through Email, Facebook, LinkedIn, Twitter, etc. A wide selection of journals (inclusive of 9 subjects, more than 200 journals)

Providing 24-hour high-quality service

User-friendly online submission system

Fair and swift peer-review system

Efficient typesetting and proofreading procedure

Display of the result of downloads and visits, as well as the number of cited articles

Maximum dissemination of your research work

Submit your manuscript at: http://papersubmission.scirp.org/

Or contact psych@scirp.org 